\title{
Impact of a diet and activity health promotion intervention on regional patterns of DNA methylation
}

\author{
Elizabeth Hibler ${ }^{1 *} \mathbb{D}$, Lei Huang ${ }^{2}$, Jorge Andrade ${ }^{2,3}$ and Bonnie Spring ${ }^{1}$
}

\begin{abstract}
Background: Studies demonstrate the impact of diet and physical activity on epigenetic biomarkers, specifically DNA methylation. However, no intervention studies have examined the combined impact of dietary and activity changes on the blood epigenome. The objective of this study was to examine the impact of the Make Better Choices 2 (MBC2) healthy diet and activity intervention on patterns of epigenome-wide DNA methylation. The MBC2 study was a 9-month randomized controlled trial among adults aged 18-65 with non-optimal levels of health behaviors. The study compared three 12-week interventions to (1) simultaneously increase exercise and fruit/ vegetable intake, while decreasing sedentary leisure screen time; (2) sequentially increase fruit/vegetable intake and decrease leisure screen time first, then increase exercise; (3) increase sleep and decrease stress (control). We collected blood samples at baseline, 3 and 9 months, and measured DNA methylation using the Illumina EPIC (850 k) BeadChip. We examined region-based differential methylation patterns using linear regression models with the false discovery rate of 0.05 . We also conducted pathway analysis using gene ontology (GO), KEGG, and IPA canonical pathway databases.

Results: We found no differences between the MBC2 population $(n=340)$ and the subsample with DNA methylation measured $(n=68)$ on baseline characteristics or the impact of the intervention on behavior change. We identified no differentially methylated regions at baseline between the control versus intervention groups. At 3 versus 9 months, we identified 154 and 298 differentially methylated regions, respectively, between controls compared to pooled samples from sequential and simultaneous groups. In the GO database, we identified two gene ontology terms related to hemophilic cell adhesion and cell-cell adhesion. In IPA analysis, we found pathways related to carcinogenesis including PIBK/AKT, Wnt/ $\beta$-catenin, sonic hedgehog, and p53 signaling. We observed an overlap between 3 and 9 months, including the GDP-L-fucose biosynthesis I, methylmalonyl metabolism, and estrogen-mediated cell cycle regulation pathways.

Conclusions: The results demonstrate that the MBC2 diet and physical activity intervention impacts patterns of DNA methylation in gene regions related to cell cycle regulation and carcinogenesis. Future studies will examine DNA methylation as a biomarker to identify populations that may particularly benefit from incorporating health behavior change into plans for precision prevention.
\end{abstract}

Keywords: Lifestyle, Randomized trial, DNA methylation, Diet, Physical activity

\footnotetext{
*Correspondence: elizabeth.hibler@northwestern.edu

'Department of Preventive Medicine, Northwestern University Feinberg

School of Medicine, 680 North Lakeshore Drive, Chicago, IL 60611, USA

Full list of author information is available at the end of the article
}

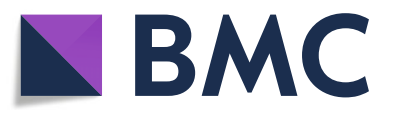

(c) The Author(s). 2019 Open Access This article is distributed under the terms of the Creative Commons Attribution 4.0 International License (http://creativecommons.org/licenses/by/4.0/), which permits unrestricted use, distribution, and reproduction in any medium, provided you give appropriate credit to the original author(s) and the source, provide a link to the Creative Commons license, and indicate if changes were made. The Creative Commons Public Domain Dedication waiver (http://creativecommons.org/publicdomain/zero/1.0/) applies to the data made available in this article, unless otherwise stated. 


\section{Background}

Large epidemiologic studies demonstrate that lifestyle choices such as a healthy diet and recommended levels of physical activity are associated with reduced risk of many chronic diseases including cardiovascular disease, diabetes, and cancer [1-5]. However, we know less regarding what biological mechanisms drive these associations at the molecular level. Health behaviors have been hypothesized to impact disease risk through epigenetic mechanisms, such as DNA methylation [6-25]. However, no studies have examined the impact of a lifestyle intervention including both dietary and physical activity components on epigenomewide patterns of DNA methylation in blood.

DNA methylation is the addition of a methyl group at cytosine-phosphate-guanine $(\mathrm{CpG})$ genomic loci and can act to suppress subsequent gene expression [26-29]. Physiologic response to both dietary intake and physical activity includes epigenetic mechanisms such as DNA methylation [30-34]. Observational studies have reported associations between physical activity and variation in patterns of DNA methylation that may impact immune function and risk of disease [6-10, 12, 35, 36]. Moreover, physical activity interventions demonstrate that physiologic effects may include reduced DNA methylation of genes associated with biological mechanisms such as inflammation, oxidative stress, and immune function [15, 17-20, 25]. However, these physical activity and exercise studies did not account for the impact of diet on DNA methylation.

Dietary intake and dietary patterns are also associated with DNA methylation in observational and randomized intervention studies [11, 14, 37-39]. Studies demonstrate that high-quality dietary intake as well as low adherence to specific dietary patterns, such as the Mediterranean Diet, are associated with hypomethylation using measures of LINE-1, or global methylation [33, 34, 37]. Global hypomehtylation in blood is associated with overall genomic instability and risk of certain cancers [33, 34, 37]. However, the majority of physical activity or dietary studies either used a candidate gene approach to examine DNA methylation in a specific gene(s) or examined levels of global DNA methylation. The current study is the first to assess the combined impact of diet and activity intervention on epigenome-wide DNA methylation.

The objective of this study was to examine the impact of the Make Better Choices 2 (MBC2) intervention on patterns of epigenome-wide DNA methylation. This approach is novel because the majority of previous studies examined either physical activity or dietary intervention alone; none included a lifestyle intervention that combined exercise, sedentary time, and dietary intake. Moreover, few studies have examined the impact of lifestyle interventions on patterns of DNA methylation in the blood as a potential marker of impact on immune function. In contrast, most studies to date examined either adipose or skeletal muscle as the target tissue of interest. The MBC2 study offers the opportunity to identify novel DNA methylation patterns associated with participation in a health behavior change intervention across multiple time points. This study is the first to examine the impact of the $\mathrm{MBC} 2$ intervention, a combined physical activity and dietary intervention,on the blood epigenome.

\section{Results}

As shown in Table 1, we found no statistically significant differences between the MBC2 population and the subsample with DNA methylation measured $(n=68)$ on baseline characteristics or the impact of the intervention on behavior change. The mean age of participants in the current study was $\sim 40$ years of age in both intervention groups and the control group. Overall, MBC2 participants were primarily women, and there was a greater frequency of women in the sample for DNA methylation compared to the overall study. However, this difference was not statistically significant. Both samples included primarily non-Hispanic/Latino individuals, but nearly equal frequencies of White vs. Black race.

In the parent study, both the sequential and simultaneous groups showed comparably large, sustained diet and activity improvements, as described previously [40]. Therefore, we compared the control group to pooled samples from the sequential and simultaneous groups. We identified no differentially methylated regions at baseline between the control versus intervention groups (data not shown). We present the top 10 differentially methylated regions along with any genes associated with that region, and gene function, at 3 and 9 months in Tables 2 and 3 , respectively. At 3 versus 9 months, we identified 154 and 298 differentially methylated regions, respectively, between controls compared to pooled samples from sequential and simultaneous groups. At 3 months, 98 of the 154 (63.6\%) regions showed a decrease in methylation versus 188 of the 298 (63.1\%) regions at 9 months. We observed primarily different regions of significance on different chromosomes between time points. However, one region on chromosome 4 (position: 185369135-185370076) showed a significant decrease in methylation between the control and intervention groups at both time points (FDR $<0.01$ ). This included three CpGs at both time points and the region maps to the IRF2 gene. We also identified two regions within chromosome 1 (position: 228756711228756714) that correspond to the DUSP5P1 gene. This region showed significantly reduced methylation between the baseline and the 3-month time points. There were three regions at 3 months and two at 9 months with either unknown function or in open reading frame uncharacterized protein regions, respectively. We present the 
Table 1 Baseline characteristics of the DNA methylation subsample from the MBC2 population

\begin{tabular}{|c|c|c|c|c|c|c|}
\hline \multirow[t]{2}{*}{ Participant characteristics } & \multicolumn{3}{|c|}{ DNA methylation $(n=68)$} & \multicolumn{3}{|c|}{ No DNA methylation $(n=144)$} \\
\hline & $\begin{array}{l}\text { Control } \\
(n=12) \\
\end{array}$ & $\begin{array}{l}\text { Simultaneous } \\
(n=25)\end{array}$ & $\begin{array}{l}\text { Sequential } \\
(n=31)\end{array}$ & $\begin{array}{l}\text { Control } \\
(n=32) \\
\end{array}$ & $\begin{array}{l}\text { Simultaneous } \\
(n=59)\end{array}$ & $\begin{array}{l}\text { Sequential } \\
(n=53)\end{array}$ \\
\hline Age, mean (SD) & $41.9(12.6)$ & $41.4(12.3)$ & $41.6(10.1)$ & $40.2(12.6)$ & $40.5(11.7)$ & $40.5(11.4)$ \\
\hline BMI, mean (SD) & $32.6(6.9)$ & $34.5(8.0)$ & $37.3(7.5)$ & $34.7(8.5)$ & $34.1(9.2)$ & $35.5(11.0)$ \\
\hline Female, $n(\%)$ & $27(87.1)$ & $55(80.9)$ & $8(66.7)$ & $38(71.7)$ & $107(74.3)$ & $25(78.1)$ \\
\hline \multicolumn{7}{|l|}{ Ethnicity, n (\%) } \\
\hline Hispanic or Latino & $4(13.3)$ & $6(9.5)$ & $1(9.1)$ & $5(9.6)$ & $14(10.0)$ & $5(15.6)$ \\
\hline Non-Hispanic or Latino & $26(86.7)$ & $58(92.1)$ & $10(90.1)$ & $47(90.4)$ & $126(90.0)$ & $27(84.4)$ \\
\hline \multicolumn{7}{|l|}{ Race, $n(\%)$} \\
\hline White & $16(51.6)$ & $30(44.1)$ & $5(41.7)$ & $24(45.3)$ & 57 (39.6) & $14(43.8)$ \\
\hline Black & $14(45.2)$ & $34(50.0)$ & $6(50.0)$ & $24(45.3)$ & $65(45.1)$ & $13(40.6)$ \\
\hline Asian & 0 & $2(3.1)$ & $1(8.3)$ & $1(1.9)$ & $6(4.2)$ & $1(3.1)$ \\
\hline Other or multiple & $1(3.2)$ & $2(3.1)$ & 0 & $4(7.5)$ & $16(11.1)$ & $4(12.5)$ \\
\hline
\end{tabular}

additional top 40 differentially methylated regions at 3 and 9 months in Additional file 1: Table S1 and S2, respectively.

We present the results from the pathway analysis in Tables 4 and 5. The analysis in the GO database (Table 4) identified two pathways related to hemophilic cell adhesion and cell-cell adhesion via the plasma membrane. The pathway included the following genes: DAB1, NECTIN4, CDH4, ROBO1, CDH9, PCDHGA1-12, and PCDHGB1-2,4-6. These genes primarily showed decreased methylation, but $D A B 1, N E C T I N 4$, and $C D H 9$ demonstrated increased methylation. We did not identify any significant pathways in the KEGG database (data not shown). In the top 20 IPA canonical pathways (presented by timepoint in Table 5), we identified pathways related to immune function and carcinogenesis in various tissues including the inflammasome, PI3K/AKT signaling, Wnt/ $\beta$-catenin, sonic hedgehog, and $\mathrm{p} 53$. We also observed an overlap in pathways between 3 and 9 months. This included differential methylation of regions related to GDP-L-fucose biosynthesis, 2-oxobutanoate degradation, estrogen-mediated cell cycle regulation, and PI3K/AKT signaling. Finally, variation between the time points also identified potential target pathways including those related to the bladder, ovarian, and colorectal cancer, specifically.

\section{Discussion}

In this study, we examined the impact of the Make Better Choices 2 intervention promoting healthy changes in diet and physical activity on regional patterns of epigenome-wide DNA methylation. The results of this study demonstrate that 12 weeks of improved lifestyle choices, focused on dietary and physical activity changes, was associated with change in DNA methylation at regions of DNA with gene functions related to immune cell metabolism, tumor suppression, and overall aging. Moreover, improved health behaviors were associated with immune cell adhesion pathways as well as several pathways critical to normal cell function and carcinogenesis. Finally, we observed some consistencies with patterns of DNA methylation over time at 3 and 9 months, but we also observed critical differences that warrant further investigation.

Previous studies examined the impact of physical activity or dietary interventions on DNA methylation in blood or circulating blood lymphocytes, but few examined an intervention incorporating both health behaviors [6-10, 41]. For example, Nakajima et al. demonstrated that moderate-intensity walking for $\geq 26 \mathrm{~min} /$ day, 2 days/week among 436 healthy adults was associated with ASC methylation [35], which controls IL-1 $\beta$ and IL-18 inflammatory cytokine expression [36]. Similarly, in the Cardiovascular Health Study, higher physical activity was associated with an anti-inflammatory phenotype via TNF hypermethylation and $I L-10$ hypomethylation [12]. Moreover, among adult endurance athletes and sedentary controls $(n=24)$, Liu et al. found 72 differentially expressed genes in blood leukocytes with genes in inflammation and oxidative stress pathways [10]. Chilton et al. found that treadmill running for $30 \mathrm{~min}$ was associated with higher TERT and SIRT6 gene expression in leukocytes, which regulate telomeres [8]. In contrast, Morabia et al. found no difference in $I L-6$ methylation in blood leukocytes between sedentary car commuting versus public transportation ( $n=180$ adults) [41]. These studies demonstrate the impact of physical activity and sedentary behavior on DNA methylation as a bloodbased biomarker of molecular mechanisms.

Studies have also examined the impact of dietary interventions among healthy adults on DNA methylation in blood, but the majority to date has focused on LINE-1 


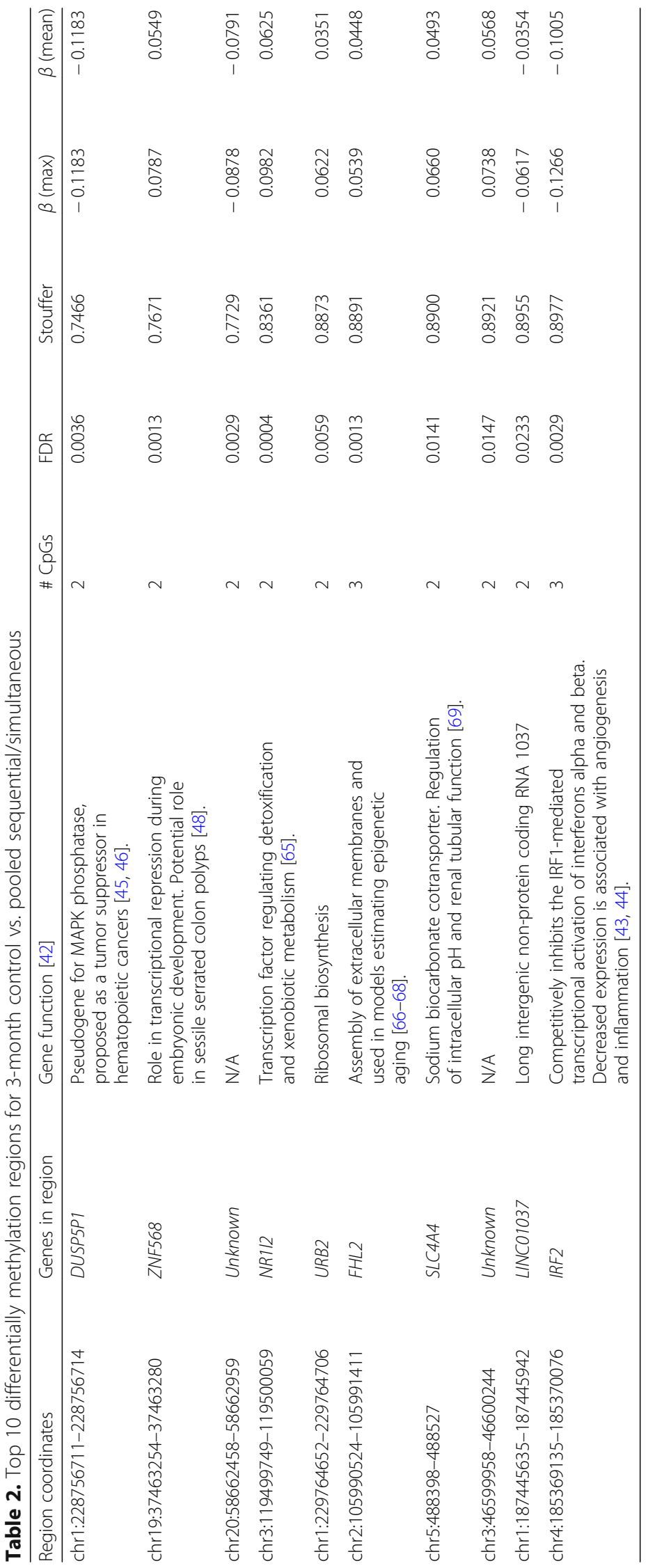




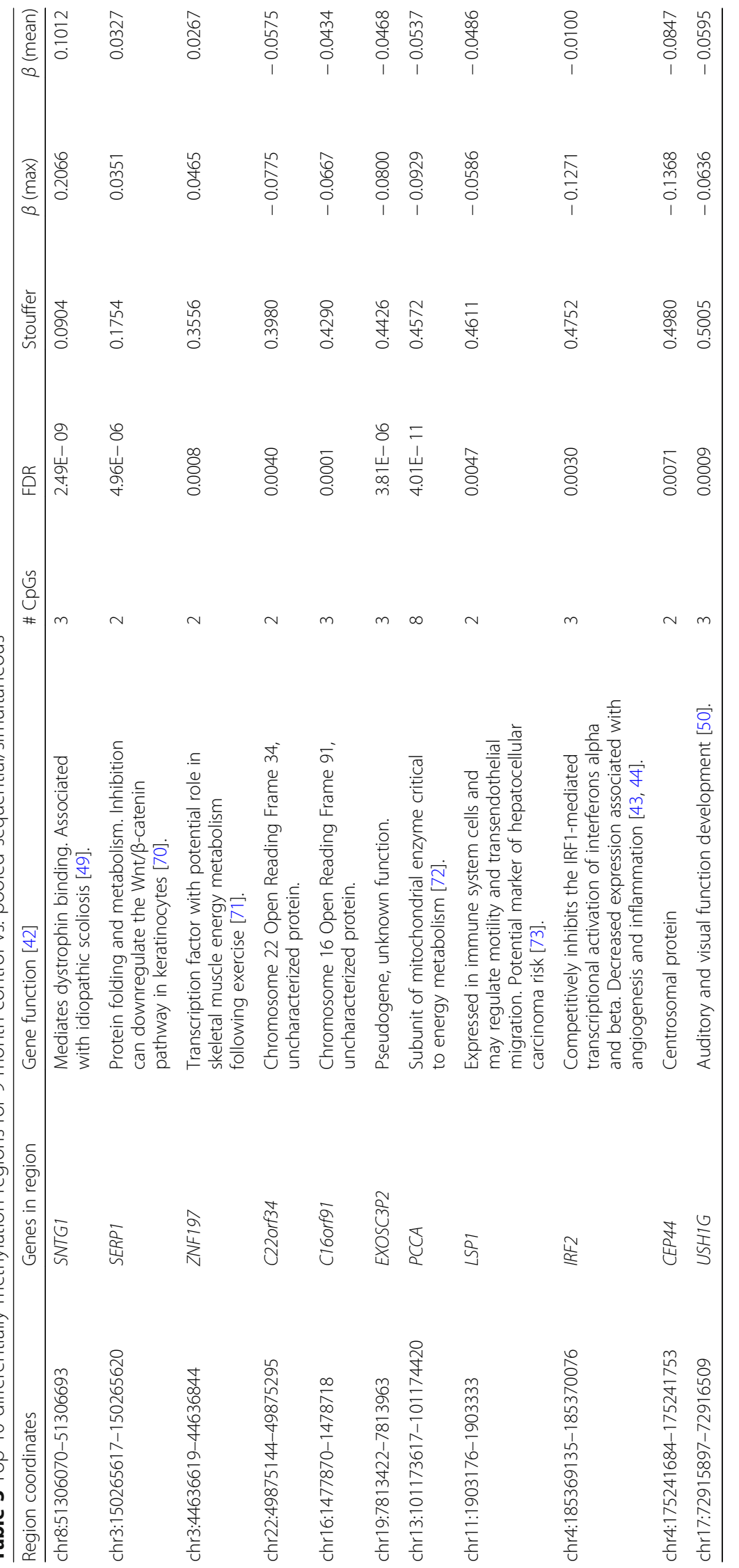


Table 4 Gene ontology results by time point from control versus pooled sequential/simultaneous

\begin{tabular}{llllll}
\hline Time point & ID & Description & Gene ratio & $p$ value & $P$ adjusted \\
\hline 3 months & GO:0007156 & Homophilic cell adhesion via plasma-membrane adhesion molecules & $23 / 123$ & $6.59 \mathrm{E}-25$ & $1.28 \mathrm{E}-21$ \\
& GO:0098742 & Cell-cell adhesion via plasma-membrane adhesion molecules & $23 / 123$ & $5.15 \mathrm{E}-21$ & $4.95 \mathrm{E}-18$ \\
\multirow{3}{*}{ months } & GO:0007156 & Homophilic cell adhesion via plasma-membrane adhesion molecules & $24 / 221$ & $3.91 \mathrm{E}-20$ & $1.23 \mathrm{E}-16$ \\
& GO:0098742 & Cell-cell adhesion via plasma-membrane adhesion molecules & $25 / 221$ & $2.87 \mathrm{E}-17$ & $4.50 \mathrm{E}-14$ \\
\hline
\end{tabular}

or candidate gene measures of DNA methylation. Studies by Agodi et al. foundation that women $(n=177)$ aged 13-50 years with low fruit consumption or folate deficiency were more likely to have LINE-1 hypomethylation in blood leukocytes (OR 3.7, 95\% 1.4-9.5 and OR 3.6, 95\% CI 1.1-12.1, respectively) [33]. Moreover, among healthy women aged $15-80$ years $(n=299)$, Barchitta et al. reported that high adherence to the Mediterranean Diet was associated with increase in LINE-1 DNA methylation in whole blood $(\beta=0.573, p<0.001)$ [34]. A recent systematic review by Aronica et al. also reported 12 intervention studies that examined the impact of dietary intervention studies on DNA methylation, but all of these examined methylation of candidate gene only [25]. Overall, these studies report that adherence to a Mediterranean Diet and/ or calorie restriction were associated with decreased DNA methylation in obesity-related genes such as $P D K 4$, KCNQ1, WT1, SH2B1, FTO, BDNF, and PPARGC1A or inflammatory genes such as TNF- $\alpha$. However, none of the studies assessed epigenome-wide patterns of DNA methylation or dietary interventions that incorporated a physical activity component.

Although some prior research examined the effect of "lifestyle" interventions on DNA methylation, only a few of these interventions included both dietary and activity components and measured methylation from blood samples. For example, Molares et al. conducted a 10-week exercise and dietary intervention among 24 adolescents and examined patterns of whole blood DNA methylation from the Infinium Human Methylation $27 \mathrm{k}$ BeadChip. The results showed that high response, as defined by reduction in BMI, was associated with differential methylation of individual CpG probes in the AQP9, DUSP22, HIPK3, TNNT1, and TNNI3 genes $(p<0.05)$. These results did not, however, incorporate adjustment for multiple comparisons. Another study by McEwen et al. examined DNA methylation (Illumina $450 \mathrm{k}$ ) in peripheral blood mononuclear cells (PBMCs) among postmenopausal women aged 55-70 following a 6-month "lifestyle" intervention that included nine 2-h sessions focusing on health education and physical activity to reduce sedentary behavior [17]. The control group participated in six 1-h sessions that focused on education related to other topics [17]. The results showed no significant associations between DNA methylation and physical activity. Another study by Delago-Cruzata et al. examined the impact of a 6-month physical activity and dietary intervention on LINE-1 or global DNA methylation in PBMCs among a diverse population of sedentary, breast cancer survivors [16]. The intervention focused on increasing physical activity to $90 \mathrm{~min} /$ week, reducing caloric intake to $1200 \mathrm{kcal} /$ day, and altering the nutrient distribution of the diet to $45 \%$ protein $/ 30 \%$ carbohydrate $/ 25 \%$ fat. The study found that LINE-1 DNA methylation was statistically significantly elevated at 6 and 12 months compared to baseline $(75.5 \%$ vs. $78.5 \%$ and $77.7 \%$, respectively; $p<0.001)$. Generalized estimated equation models also demonstrated that increased fruit/vegetable intake was associated with an increase in DNA methylation $(\beta=0.0118,95 \% \mathrm{CI}=0.002-0.022)$ [16]. As described, few studies have examined epigenome-wide methylation in blood, and none to date have used the EPIC $850 \mathrm{k}$ chip. Moreover, the majority of dietary interventions have tested caloric restriction to produce weight loss as opposed to improved dietary quality, such as increased consumption of fruits and vegetables, and the structure of physical activity interventions also varied. Nonetheless, the results of previous studies are consistent with the present findings in suggesting that lifestyle interventions designed to improve diet and physical activity can change patterns of DNA methylation in blood cells.

We identified over 150 differentially methylated regions at both time points. Within the top 10 most significant regions, the only consistent finding was that methylation of the region on chromosome 4 (position: 185369135-185370076) $(\mathrm{FDR}=0.003)$ decreased at both time points $\left(\beta_{\max }=-0.1266\right.$ and -0.1271 at 3 and 9 months, respectively). This region includes the interferon regulatory factor 2 (IRF2) gene, which inhibits IRF1mediated transcriptional activation of interferons alpha and beta [42]. We observed a decrease in methylation following the $\mathrm{MBC} 2$ intervention, which may be associated with increased expression of IRF2 and, in turn, decreased angiogenesis and inflammation [43, 44].

The other top regions varied between the 3- and 9-month time points, but include genes with a known function related to overall health and disease risk. At 3 months, we identified two regions on chromosome 1 associated with decreased methylation of the DUSP5P1 pseudogene in the family of MAPK phosphatases. Studies suggest that this gene may act 
Table 5 Top 20 IPA Canonical Pathways by time point for control versus pool sequential/simultaneous

\begin{tabular}{|c|c|c|}
\hline Ingenuity canonical pathways & $-\log (p$ value $)$ & Ratio \\
\hline \multicolumn{3}{|l|}{3 months } \\
\hline GDP-L-fucose Biosynthesis I (from GDP-D-mannose) & 1.89 & 0.500 \\
\hline Methylmalonyl pathway & 1.59 & 0.250 \\
\hline 2-Oxobutanoate degradation I & 1.49 & 0.200 \\
\hline PI3K/AKT signaling & 1.33 & 0.024 \\
\hline GM-CSF signaling & 1.08 & 0.027 \\
\hline Colanic acid building blocks biosynthesis & 1.06 & 0.071 \\
\hline Wnt/ß-catenin signaling & 1.01 & 0.018 \\
\hline Mitochondrial L-carnitine shuttle pathway & 0.98 & 0.059 \\
\hline Bladder cancer signaling & 0.96 & 0.023 \\
\hline GADD45 signaling & 0.93 & 0.053 \\
\hline Acute myeloid leukemia signaling & 0.92 & 0.022 \\
\hline Inflammasome pathway & 0.91 & 0.050 \\
\hline Pyrimidine deoxyribonucleotides de novo biosynthesis I & 0.85 & 0.044 \\
\hline Estrogen-mediated S-phase entry & 0.81 & 0.039 \\
\hline Sonic hedgehog signaling & 0.76 & 0.035 \\
\hline Sperm motility & 0.73 & 0.017 \\
\hline LXR/RXR activation & 0.73 & 0.017 \\
\hline FXR/RXR activation & 0.71 & 0.016 \\
\hline Circadian rhythm signaling & 0.70 & 0.029 \\
\hline \multicolumn{3}{|l|}{9 months } \\
\hline GDP-L-fucose biosynthesis I (from GDP-D-mannose) & 1.65 & 0.500 \\
\hline Estrogen-mediated S-phase entry & 1.47 & 0.077 \\
\hline Glioblastoma multiforme signaling & 1.45 & 0.031 \\
\hline p53 signaling & 1.44 & 0.036 \\
\hline Methylmalonyl pathway & 1.36 & 0.250 \\
\hline PI3K/AKT signaling & 1.30 & 0.033 \\
\hline 2-Oxobutanoate degradation I & 1.26 & 0.200 \\
\hline Cell cycle regulation by BTG family proteins & 1.19 & 0.054 \\
\hline NAD biosynthesis from 2-amino-3-carboxymuconate semialdehyde & 1.18 & 0.167 \\
\hline nNOS signaling in skeletal muscle cells & 1.13 & 0.050 \\
\hline Bladder cancer signaling & 1.13 & 0.035 \\
\hline Phosphatidylcholine biosynthesis I & 1.12 & 0.143 \\
\hline tRNA splicing & 1.11 & 0.049 \\
\hline Ovarian cancer signaling & 1.11 & 0.028 \\
\hline Role of p14/p19ARF in tumor suppression & 1.09 & 0.048 \\
\hline Phosphatidylethanolamine biosynthesis ॥ & 1.06 & 0.125 \\
\hline Gustation pathway & 1.05 & 0.027 \\
\hline GABA receptor signaling & 1.05 & 0.032 \\
\hline Role of Oct4 in mammalian embryonic stem cell pluripotency & 1.04 & 0.044 \\
\hline
\end{tabular}

as a tumor suppressor in hematopoietic malignancies $[45,46]$. In the current study, we observed a decrease in methylation following the MBC2 intervention, which may indicate an upregulation of
DUSP5P1 and tumor suppression. Kong et al. found that, among non-small cell lung cancer cases $(n=37)$ compared to controls $(n=17)$, NR1I2 (aka PXR) expression was significantly higher among non-small cell lung 
cancer tumors compared to peripheral blood mononuclear cells [47]. We also observed that methylation increased in this region following $\mathrm{MBC} 2$, which may indicate that a healthier lifestyle downregulates the protein in immune cells. In contrast, a small study by Andrew et al. found that $Z N F 568$, a zinc finger transcription factor, was hypermethylated in sessile serrated colon polyps $(n=34)$ compared to normal adjacent mucosal tissue $(n=15)$ [48]. We also observed an increase in ZNF568 methylation following improved health behaviors at only 9 months. However, gene function may be tissuespecific and we identified no studies that examined DNA methylation of many of the top 10 genes in cells from whole blood.

At the 9-month time point, we also observed differentially methylated gene regions. The SNTG1 gene is a cytoplasmic membrane protein that associates with the Duchenne muscular dystrophy gene, dystrophin [42]. Studies have shown that mutations leading to reduced production of this protein are associated with idiopathic scoliosis [49]. We observed an increase in methylation of SNTG1 at 9 months, which could lead to decreased expression of the protein. We also observed decreased methylation of the USH1G, a gene critical to proper visual and auditory function [50]. Moreover, we observed increased methylation of the $P C C A$, which is an enzyme critical to proper function of the tricarboxylic acid (aka Krebs or TCA) cycle and energy production in muscle, both cardiac and skeletal $[51,52]$. In circulating blood leukocytes, the TCA cycle is upregulated in the presence of proinflammatory signals [53]. However, studies also show that habitual healthy lifestyle reduces methylation of proinflammatory genes [12]. Thus, the observed increase in PCCA methylation may reflect a decrease in systemic inflammation following $\mathrm{MBC} 2$ participation, which should be measured in future studies. Overall, the present results are consistent with other studies suggesting that the types of diet and activity improvements produced in the $\mathrm{MBC} 2$ study affect molecular processes that play an integral role in promoting overall health.

Pathway analysis also identified gene pathways that may be important for understanding the impact of lifestyle on biological mechanisms that affect risk for developing chronic diseases. We identified the cell adhesion pathway in the GO database as significant at both 3 and 9 months. The importance of cell adhesion pathways in immune function is interesting in the context of health behaviors. We know that activation of the immune system to target areas of inflammation or infection involves leukocyte recruitment and transmigration to the site of activity via the vasculature [54]. However, when individuals habitually practice healthy behaviors and levels of systemic inflammation are lower, it is possible that genes associated with the transmigration of immune system cells could be downregulated. Yet, in comparing our results to the current literature, we identified no studies that examined a combined lifestyle intervention among healthy adults with DNA methylation pathway analysis. However, a recent study by Turner et al. examined the impact of chronic versus acute resistance exercise on DNA methylation pathways in the skeletal muscle [55]. Even though this study only used the KEGG pathway database, the results identified several significant pathways related to cancer including those related to proteoglycans, transcriptional regulation, colorectal cancer, and small cell lung cancer. Similarly, in the IPA pathway analysis, we identified pathways related to carcinogenesis (e.g., PI3K/AKT signaling, Wnt/ $\beta$-catenin, sonic hedgehog, and p53 pathways) and some specific to cancers like bladder, ovarian, and brain. Additional studies are needed to refine understanding of the impact of exercise type, intensity, and duration on molecular mechanisms of immune system cells in the blood.

Overall, our study has several strengths, but also limitations. This study is the first randomized controlled trial to examine the impact of a joint physical activity and dietary intervention on DNA methylation using the Illumina $850 \mathrm{k}$ EPIC chip over three time points. The limitations of this study include a relatively small sample size, which likely curtails our ability to detect small changes in methylation status. This study also included both White and African-American participants, but the sample size was not large enough to allow for stratification. Furthermore, there is always a chance for inaccurate self-report of dietary habits. Future studies will include a larger sample and additional measurement time points during the intervention as well as following its conclusion. This will allow us to examine the persistence of the observed changes in DNA methylation.

\section{Conclusions}

The results demonstrate that the $\mathrm{MBC} 2$ intervention, which improved diet and physical activity among inactive adults with suboptimal diet quality, impacts patterns of DNA methylation in gene regions related to inflammation, carcinogenesis, and chronic disease. Understanding the biological mechanisms affected by lifestyle interventions may help us to better identify individuals who may most benefit, on a molecular level, from healthy lifestyle change. These preliminary results will inform future studies to examine DNA methylation as a potential biomarker identifying populations that may particularly benefit from incorporating health behavior change into plans for precision prevention of chronic diseases. 


\section{Methods}

\section{Make Better Choices 2 (MBC2) study population and} intervention design

MBC2 was a 9-month randomized controlled trial (RCT) conducted between 2012 and 2014 among adults $(n=68)$ aged 18-65 with non-optimal levels of all of 4 lifestyle behaviors: fruits/vegetables, saturated fats, sedentary leisure screen time, and moderate-vigorous physical activity (MVPA) [40, 56]. Specifically, this included the following thresholds for diet: $<5$ servings of fruits and vegetables per day and $\geq 8 \%$ daily calories from saturated fat; physical activity: < $150 \mathrm{~min}$ per week MVPA; and sedentary behavior: $>120$ min per week of leisure screen time from sources such as television or video games [40]. The MBC2 participants were randomly assigned to one of three 12-week treatments using a smartphone application and remote coaching to (1) increase MVPA while improving fruits/vegetables and sedentary leisure (simultaneous), (2) improve fruits/ vegetables and sedentary leisure first, followed by MVPA (sequential), or (3) improve stress and sleep (control). The study examined a standardized composite diet and physical activity improvement score measured by 1-week assessments when participants wore an accelerometer and self-monitored all behaviors on a smart phone. The primary study outcome was sustained improvement from baseline through 9-month follow-up, and the secondary outcomes were improvement in individual diet and activity behaviors. In the original study, sequential and simultaneous interventions produced similar and sustained diet and activity improvement compared to control $(p<0.001)$, and the effects were comparable between intervention groups [40].

\section{DNA methylation}

We examined patterns of DNA methylation in whole blood samples from 68 participants who had the most complete repeated assessments of behavior and blood, and, who for intervention participants, showed the most behavior change on composite $\mathrm{MBC} 2$ outcome measurement. These participants included 25 from the simultaneous intervention arm, 31 from sequential intervention arm, and 12 from the control group. We conducted DNA methylation profiling at three time points (baseline, 3 months, and 9 months) for each participant. We analyzed 204 blood samples for this study. We extracted DNA from the whole blood using the QIAamp DNA Blood Kit (QIAGEN, Valencia, CA, USA). Bisulfite conversion was completed using the EZ-96 DNA Methylation Kit (Zymo Research, Orange, CA, USA). We then measured DNA methylation of $\mathrm{CpG}$ probes using Illumina EPIC BeadChip (850 k array) [57].

We collaborated with the University of Chicago Center for Research Informatics for data processing, quality control, and statistical analysis. The bioinformatics and data analysis workflow are shown in Additional file 1: Figure S1. First, we imported the raw methylation data from IDAT files using read.metharray.exp function implemented in minfi package. For quality control, we calculated the detection $p$ value for every $\mathrm{CpG}$ in every sample and plotted the mean detection $p$ value for each sample, which allowed us to assess the general quality of the samples in terms of the overall signal reliability. We found no low-quality samples in this study. For normalization, we first performed the background correction using Noob method from minfi package $[58,59]$. Since we are comparing different blood samples, which are globally relatively similar, we applied the preprocessQuantile method to our data. This function implements a stratified quantile-normalization procedure, which we applied to the methylated and unmethylated signal intensities separately to account for different probe types. We obtained the normalized data in two forms, betavalue (the ratio of the methylated probe intensity and the sum of methylated and unmethylated probe intensities), and $M$-value (log2 ratio of the intensities of methylated probe versus unmethylated probe).

We also filtered poor-performing probes before differential methylation analysis. We removed probes based on the following criteria: (1) detection $p$ value $<0.01$, (2) $5 \%$ samples with a beadcount $<3$, (3) no guanine or cytosine bases, (4) probes on the sex chromosomes, (5) probes with SNPs at CpG site or single-base extension site, (6) polymorphic probes [60], (7) cross-reactive probes $[60,61]$, and (8) probes that align to multiple locations [62]. Following this filtering, we reduced the number of probes from 866,836 to 749,545 for downstream analysis. Moreover, we examined batch effects using singular-value decomposition (SVD) and multidimensional scaling plot. To account for potential batch effects consisting of both categorical and continuous covariates, we applied the surrogate variable analysis (SVA) method implemented in sva package to adjust the normalized M-values for any known, unknown, unmodeled, or latent sources of noise, including demographic and other participant characteristics [63].

\section{Statistical analysis}

We conducted region-based differential methylation analysis. While examination of probe-wise differential methylation has utility when single-CpG sites are associated with a phenotype, differentially methylated regions (DMRs) are often more predictive. This is because small differences at any individual site are persistent across a region, statistical power to detect them may be greater in regional analysis compared to probe-wise analysis. Thus, we conducted differential methylation regional analysis for 11 comparisons using the DMRcate package [64]. The differentially methylated regions were 
identified using an FDR adjusted $p$ value of 0.05 as well as Stouffer transformed values. We compared control versus pooled sequential and simultaneous intervention groups at baseline, 3 months, and 9 months following the intervention period. We also compared the sequential versus simultaneous groups at 3- and 9-month visits.

For pathway analysis, we then converted the regions to annotated genomic ranges, which uses the genome annotations to annotate overlapping promoter regions ( \pm $2000 \mathrm{bp}$ from TSS). We annotated regions with Ensembl Genome Release 75 (February 2014). To gain an understanding of the biological processes that the differentially methylated CpGs may be involved in, we performed gene ontology, KEGG pathway, and MSigDB canonical pathway (http://software.broadinstitute.org/gsea/msigdb) analyses using the gometh function in the missMethyl package. We also performed Ingenuity Pathway Analysis (IPA) core analysis. We conducted all analyses using $\mathrm{R}$ version 3.4.1 and Bioconductor version 3.5.

\section{Additional file}

Additional file 1: Figure S1. Bioinformatics and data analysis pipeline. Table S1. Top 40 differentially regions between control vs. pooled sequential/simultaneous at 3 months. Table S2. Top 40 differentially regions between control vs. pooled sequential/simultaneous at 9 months. (DOCX $710 \mathrm{~kb})$

\section{Acknowledgements}

N/A

\section{Authors' contributions}

For author contributions, BS designed and conducted the MBC2 trial, EH assisted with the data analysis and interpretation and wrote the manuscript, and $\mathrm{LH}$ and JA conducted the bioinformatics analysis. All authors read and contributed to the final preparation of the manuscript. All authors read and approved the final manuscript.

\section{Funding}

This study was registered as NCT01249989 at clinicaltrials.gov on November 20, 2010 (https://clinicaltrials.gov/ct2/show/NCT01249989). This work was supported by NHLBI R01 HL075451 (Spring), P30CA60553 (Robert H. Lurie Comprehensive Center, Northwestern University) NCATS UL1TR000150 (Northwestern University), NIH 5UL1TR002389-02 (University of Chicago), and $\mathrm{NIH}$ P30CA014599 (The University of Chicago Comprehensive Cancer Center)

\section{Availability of data and materials}

The datasets used during the current study are available from the corresponding author on reasonable request.

\section{Ethics approval and consent to participate}

The study was approved by the Northwestern University human subjects protection program, and all subjected consented prior to participation.

\section{Consent for publication}

N/A

\section{Competing interests}

The authors declare that they have no competing interests.

\section{Author details}

${ }^{1}$ Department of Preventive Medicine, Northwestern University Feinberg School of Medicine, 680 North Lakeshore Drive, Chicago, IL 60611, USA.
${ }^{2}$ Center for Research Informatics, Biological Sciences Division, University of Chicago, 900 E. 57th. Street, Chicago, IL 60637, USA. ${ }^{3}$ Department of Pediatrics, The University of Chicago, 900 E. 57th. Street, Chicago, IL 60637, USA.

Received: 29 April 2019 Accepted: 15 July 2019

Published online: 11 September 2019

\section{References}

1. Chowdhury PP, Mawokomatanda T, Xu F, Gamble S, Flegel D, Pierannunzi C, et al. Surveillance for Certain Health Behaviors, Chronic Diseases, and Conditions, Access to Health Care, and Use of Preventive Health Services Among States and Selected Local Areas- Behavioral Risk Factor Surveillance System, United States, 2012. Morb Mortal Wkly Rep Surveill Summ (Washington, DC: 2002). 2016;65(4):1-142.

2. Giles-Corti B, Sallis JF, Sugiyama T, Frank LD, Lowe M, Owen N. Translating active living research into policy and practice: One important pathway to chronic disease prevention. J Public Health Policy. 2015.

3. Harvie M, Howell A, Evans DG. Can diet and lifestyle prevent breast cancer: what is the evidence? Am Soc Clin Oncol Educ Book / ASCO Am Soc Clin Oncol Meet. 2015:e66-73.

4. Akin $\mathrm{H}$, Tözün N. Diet, microbiota, and colorectal cancer. J Clin Gastroenterol. 2014;48(Suppl 1):S67-9.

5. Murray CJL, Atkinson C, Bhalla K, Birbeck G, Burstein R, Chou D, et al. The state of US health, 1990-2010: burden of diseases, injuries, and risk factors. JAMA. 2013;310(6):591-608.

6. White AJ, Sandler DP, Bolick SC, Xu Z, Taylor JA, DeRoo LA. Recreational and household physical activity at different time points and DNA global methylation. Eur J Cancer. 2013;49(9):2199-206.

7. Zhang FF, Cardarelli R, Carroll J, Zhang S, Fulda KG, Gonzalez K, et al. Physical activity and global genomic DNA methylation in a cancer-free population. Epigenetics. 2011;6(3):293-9.

8. Chilton WL, Marques FZ, West J, Kannourakis G, Berzins SP, O'Brien BJ, et al. Acute exercise leads to regulation of telomere-associated genes and microRNA expression in immune cells. PLoS ONE. 2014;9(4):e92088.

9. Broadbent J, Sampson D, Sabapathy S, Haseler LJ, Wagner KH, Bulmer AC, et al. Gene networks in skeletal muscle following endurance exercise are coexpressed in blood neutrophils and linked with blood inflammation markers. J Appl Physiol (1985). 2017;122(4):752-66.

10. Liu D, Wang R, Grant AR, Zhang J, Gordon PM, Wei Y, et al. Immune adaptation to chronic intense exercise training: new microarray evidence. BMC Genomics. 2017;18(1):29.

11. Bishop KS, Ferguson LR. The interaction between epigenetics, nutrition and the development of cancer. Nutrients. 2015;7(2):922-47.

12. Horsburgh S, Robson-Ansley P, Adams R, Smith C. Exercise and inflammation-related epigenetic modifications: focus on DNA methylation. Exerc Immunol Rev. 2015;21:26-41.

13. Ling C, Rönn T. Epigenetic adaptation to regular exercise in humans. Drug Discov Today. 2014;19(7):1015-8.

14. Zhang FF, Morabia A, Carroll J, Gonzalez K, Fulda K, Kaur M, et al. Dietary patterns are associated with levels of global genomic DNA methylation in a cancer-free population. J Nutr. 2011:141(6):1165-71.

15. Barres R, Yan J, Egan B, Treebak JT, Rasmussen M, Fritz T, et al. Acute exercise remodels promoter methylation in human skeletal muscle. Cell Metab. 2012;15(3):405-11.

16. Delgado-Cruzata L, Zhang W, McDonald JA, Tsai WY, Valdovinos C, Falci L, et al. Dietary modifications, weight loss, and changes in metabolic markers affect global DNA methylation in Hispanic, African American, and AfroCaribbean breast cancer survivors. J Nutr. 2015;145(4):783-90.

17. McEwen LM, Gatev EG, Jones MJ, Maclsaac JL, McAllister MM, Goulding RE, et al. DNA methylation signatures in peripheral blood mononuclear cells from a lifestyle intervention for women at midlife: a pilot randomized controlled trial. Appl Physiol Nutr Metab. 2018;43(3):233-9.

18. Laker RC, Garde C, Camera DM, Smiles WJ, Zierath JR, Hawley JA, et al. Transcriptomic and epigenetic responses to short-term nutrient-exercise stress in humans. Sci Rep. 2017;7(1):15134

19. Nitert MD, Dayeh T, Volkov P, Elgzyri T, Hall E, Nilsson E, et al. Impact of an exercise intervention on DNA methylation in skeletal muscle from firstdegree relatives of patients with type 2 diabetes. Diabetes. 2012;61(12): 3322-32. 
20. Ronn T, Volkov P, Davegardh C, Dayeh T, Hall E, Olsson AH, et al. A six months exercise intervention influences the genome-wide DNA methylation pattern in human adipose tissue. PLoS Genet. 2013;9(6): e1003572.

21. Hjort L, Jorgensen SW, Gillberg L, Hall E, Brons C, Frystyk J, et al. 36 h fasting of young men influences adipose tissue DNA methylation of LEP and ADIPOQ in a birth weight-dependent manner. Clin Epigenetics. 2017;9:40.

22. Perfilyev A, Dahlman I, Gillberg L, Rosqvist F, Iggman D, Volkov P, et al. Impact of polyunsaturated and saturated fat overfeeding on the DNAmethylation pattern in human adipose tissue: a randomized controlled trial. Am J Clin Nutr. 2017;105(4):991-1000.

23. Gillberg L, Perfilyev A, Brons C, Thomasen M, Grunnet LG, Volkov P, et al. Adipose tissue transcriptomics and epigenomics in low birthweight men and controls: role of high-fat overfeeding. Diabetologia. 2016;59(4):799-812.

24. Pirini F, Rodriguez-Torres S, Ayandibu BG, Orera-Clemente M. Gonzalez-de la Vega A, Lawson F, et al. INSIG2 rs7566605 single nucleotide variant and global DNA methylation index levels are associated with weight loss in a personalized weight reduction program. Mol Med Rep. 2018;17(1):1699-709.

25. Aronica L, Levine AJ, Brennan K, Mi J, Gardner C, Haile RW, et al. A systematic review of studies of DNA methylation in the context of a weight loss intervention. Epigenomics. 2017;9(5):769-87.

26. Ficz G, Gribben JG. Loss of 5-hydroxymethylcytosine in cancer: cause or consequence? Genomics. 2014;104(5):352-7.

27. Hespe GE, Kataru RP, Savetsky IL, Garcia Nores GD, Torrisi JS, Nitti MD, et al. Exercise training improves obesity-related lymphatic dysfunction. J Physiol. 2016;594(15):4267-82.

28. Moarii M, Boeva V, Vert J-P, Reyal F. Changes in correlation between promoter methylation and gene expression in cancer. BMC Genomics. 2015;16(1):873.

29. Wagner JR, Busche S, Ge B, Kwan T, Pastinen T, Blanchette M. The relationship between DNA methylation, genetic and expression interindividual variation in untransformed human fibroblasts. Genome Biol. 2014;15(2):R37.

30. Friedenreich CM, Neilson HK, Lynch BM. State of the epidemiological evidence on physical activity and cancer prevention. Eur J Cancer. 2010; 46(14):2593-604.

31. Henson J, Yates T, Edwardson CL, Khunti K, Talbot D, Gray LJ, et al. Sedentary time and markers of chronic low-grade inflammation in a high risk population. PLoS ONE. 2013;8(10):e78350.

32. Pareja-Galeano H, Sanchis-Gomar F, Garcia-Gimenez JL. Physical exercise and epigenetic modulation: elucidating intricate mechanisms. Sports Med. 2014;44(4):429-36.

33. Agodi A, Barchitta M, Quattrocchi A, Maugeri A, Canto C, Marchese AE, et al. Low fruit consumption and folate deficiency are associated with LINE-1 hypomethylation in women of a cancer-free population. Genes Nutr. 2015;10(5):30.

34. Barchitta M, Maugeri A, Quattrocchi A, Barone G, Mazzoleni P, Catalfo A, et al. Mediterranean Diet and Particulate Matter Exposure Are Associated With LINE-1 Methylation: Results From a Cross-Sectional Study in Women. Front Genet. 2018;9:514.

35. Nakajima K, Takeoka M, Mori M, Hashimoto S, Sakurai A, Nose H, et al. Exercise effects on methylation of ASC gene. Int J Sports Med. 2010;31(9):671-5.

36. Sun Q, Fan J, Billiar TR, Scott MJ. Inflammasome and autophagy regulation a two-way street. Mol Med. 2017;23:188.

37. Zhang FF, Santella RM, Wolff M, Kappil MA, Markowitz SB, Morabia A. White blood cell global methylation and IL-6 promoter methylation in association with diet and lifestyle risk factors in a cancer-free population. Epigenetics. 2012;7(6):606-14

38. Chen J, Xu X. 8 - Diet, Epigenetic, and Cancer Prevention. In: Ushijima ZH, Toshikazu, editors. Adv Genet. Epigenetics and Cancer, Part B. 71: Academic Press; 2010. p. 237-55.

39. Slattery ML, Curtin K, Sweeney C, Levin TR, Potter J, Wolff RK, et al. Diet and lifestyle factor associations with $\mathrm{CpG}$ island methylator phenotype and BRAF mutations in colon cancer. Int J Cancer. 2007:120(3):656-63.

40. Spring B, Pellegrini C, McFadden HG, Pfammatter AF, Stump TK, Siddique J, et al. Multicomponent mHealth Intervention for Large, Sustained Change in Multiple Diet and Activity Risk Behaviors: The Make Better Choices 2 Randomized Controlled Trial. J Med Internet Res. 2018;20(6):e10528.

41. Morabia A, Zhang FF, Kappil MA, Flory J, Mirer FE, Santella RM, et al. Biologic and epigenetic impact of commuting to work by car or using public transportation: a case-control study. Prev Med. 2012;54(3-4):229-33.
42. Stelzer G, Rosen N, Plaschkes I, Zimmerman S, Twik M, Fishilevich S, et al. The GeneCards Suite: From Gene Data Mining to Disease Genome Sequence Analyses. Curr Protoc Bioinformatics. 2016;54(1):1.30.1-1.30.33.

43. Kawaguchi M, Oka T, Sugaya M, Suga H, Kimura T, Morimura S, et al. IRF-2 haploinsufficiency causes enhanced imiquimod-induced psoriasis-like skin inflammation. J Dermatol Sci. 2018:90(1):35-45.

44. Sun H, Wang Y. Interferon Regulatory Factors in Heart. Hypertension. 2014; 63(4):663-4.

45. Zhou LY, Yin JY, Tang Q, Zhai LL, Zhang TJ, Wang YX, et al. High expression of dual-specificity phosphatase 5 pseudogene 1 (DUSP5P1) is associated with poor prognosis in acute myeloid leukemia. Int I Clin Exp Pathol. 2015; 8(12):16073-80.

46. Staege MS, Muller K, Kewitz S, Volkmer I, Mauz-Korholz C, Bernig T, et al. Expression of dual-specificity phosphatase 5 pseudogene 1 (DUSP5P1) in tumor cells. PLoS ONE. 2014:9(2):e89577.

47. Kong Q, Han Z, Zuo X, Wei H, Huang W. Co-expression of pregnane X receptor and ATP-binding cassette sub-family B member 1 in peripheral blood: A prospective indicator for drug resistance prediction in non-small cell lung cancer. Oncol Lett. 2016;11(5):3033-9.

48. Andrew AS, Baron JA, Butterly LF, Suriawinata AA, Tsongalis GJ, Robinson CM, et al. Hyper-Methylated Loci Persisting from Sessile Serrated Polyps to Serrated Cancers. Int J Mol Sci. 2017;18(3).

49. Bashiardes S, Veile R, Allen M, Wise CA, Dobbs M, Morcuende JA, et al. SNTG1, the gene encoding gamma1-syntrophin: a candidate gene for idiopathic scoliosis. Hum Genet. 2004;115(1):81-9.

50. Trouillet A, Dubus E, Degardin J, Estivalet A, Ivkovic I, Godefroy D, et al. Cone degeneration is triggered by the absence of USH1 proteins but prevented by antioxidant treatments. Sci Rep. 2018;8(1):1968.

51. Gibala MJ, Young ME, Taegtmeyer H. Anaplerosis of the citric acid cycle: role in energy metabolism of heart and skeletal muscle. Acta Physiol Scand. 2000;168(4):657-65.

52. Wongkittichote P, Ah Mew N, Chapman KA. Propionyl-CoA carboxylase - A review. Mol Genet Metab. 2017;122(4):145-52.

53. Ryan DG, O'Neill LAJ. Krebs cycle rewired for macrophage and dendritic cell effector functions. FEBS Lett. 2017;591(19):2992-3006.

54. Leick M, Azcutia V, Newton G, Luscinskas FW. Leukocyte recruitment in inflammation: basic concepts and new mechanistic insights based on new models and microscopic imaging technologies. Cell Tissue Res. 2014; 355(3):647-56.

55. Turner DC, Seaborne RA, Sharples AP. Comparative Transcriptome and Methylome Analysis in Human Skeletal Muscle Anabolism, Hypertrophy and Epigenetic Memory. Sci Rep. 2019;9(1):4251.

56. Pellegrini CA, Steglitz J, Johnston W, Warnick J, Adams T, McFadden HG, et al. Design and protocol of a randomized multiple behavior change trial: Make Better Choices 2 (MBC2). Contemp Clin Trials. 2015;41:85-92.

57. Bibikova M, Barnes B, Tsan C, Ho V, Klotzle B, Le JM, et al. High density DNA methylation array with single $\mathrm{CpG}$ site resolution. Genomics. 2011; 98(4):288-95.

58. Triche TJ Jr, Weisenberger DJ, Van Den Berg D, Laird PW, Siegmund KD. Low-level processing of Illumina Infinium DNA Methylation BeadArrays. Nucleic Acids Res. 2013;41(7):e90.

59. Fortin JP, Triche TJ Jr, Hansen KD. Preprocessing, normalization and integration of the Illumina HumanMethylationEPIC array with minfi. Bioinformatics. 2017;33(4):558-60.

60. McCartney DL, Walker RM, Morris SW, McIntosh AM, Porteous DJ, Evans KL. Identification of polymorphic and off-target probe binding sites on the Illumina Infinium MethylationEPIC BeadChip. Genomics Data. 2016;9:22-4.

61. Chen YA, Lemire M, Choufani S, Butcher DT, Grafodatskaya D, Zanke BW, et al. Discovery of cross-reactive probes and polymorphic CpGs in the Illumina Infinium HumanMethylation450 microarray. Epigenetics. 2013:8(2):203-9.

62. Nordlund J, Backlin C, Raine A. Computational and Statistical Analysis of Array-Based DNA Methylation Data. Methods Mol Biol. 2019;1878: $173-91$.

63. Leek JT, Johnson WE, Parker HS, Jaffe AE, Storey JD. The sva package for removing batch effects and other unwanted variation in high-throughput experiments. Bioinformatics. 2012;28(6):882-3.

64. Peters TJ, Buckley MJ, Statham AL, Pidsley R, Samaras K, R VL, et al. De novo identification of differentially methylated regions in the human genome. Epigenetics Chromatin. 2015;8:6.

65. Ma X, Chen J, Tian Y. Pregnane $X$ receptor as the "sensor and effector" in regulating epigenome. J Cell Physiol. 2015;230(4):752-7. 
66. Durso DF, Bacalini MG, Sala C, Pirazzini C, Marasco E, Bonafe M, et al. Acceleration of leukocytes' epigenetic age as an early tumor and sexspecific marker of breast and colorectal cancer. Oncotarget. 2017;8(14): 23237-45.

67. Jung SE, Lim SM, Hong SR, Lee EH, Shin KJ, Lee HY. DNA methylation of the ELOVL2, FHL2, KLF14, C1orf132/MIR29B2C, and TRIM59 genes for age prediction from blood, saliva, and buccal swab samples. Forensic Sci Int Genet. 2019;38:1-8.

68. Spolnicka M, Zbiec-Piekarska R, Karp M, Machnicki MM, Wlasiuk P, Makowska $Z$, et al. DNA methylation signature in blood does not predict calendar age in patients with chronic lymphocytic leukemia but may alert to the presence of disease. Forensic Sci Int Genet. 2018;34:e15-e7.

69. Argos M, Chen L, Jasmine F, Tong L, Pierce BL, Roy S, et al. Gene-specific differential DNA methylation and chronic arsenic exposure in an epigenome-wide association study of adults in Bangladesh. Environ Health Perspect. 2015;123(1):64-71.

70. Zhang G, Song K, Yan H. MicroRNA-124 represses wound healing by targeting SERP1 and inhibiting the Wnt/beta-catenin pathway. Adv Clin Exp Med. 2019

71. Ström K, Morales-Alamo D, Ottosson F, Edlund A, Hjort L, Jörgensen SW, et al. $N(1)-$-methylnicotinamide is a signalling molecule produced in skeletal muscle coordinating energy metabolism. Sci Rep. 2018:8(1):3016.

72. Husek P, Pacovsky J, Chmelarova M, Podhola M, Brodak M. Methylation status as a predictor of intravesical Bacillus Calmette-Guerin (BCG) immunotherapy response of high grade non-muscle invasive bladder tumor. Biomed Pap Med Fac Univ Palacky Olomouc Czech. 2017:161(2):210-6.

73. Lubecka K, Flower K, Beetch M, Qiu J, Kurzava L, Buvala H, et al. Loci-specific differences in blood DNA methylation in HBV-negative populations at risk for hepatocellular carcinoma development. Epigenetics. 2018;13(6):605-26.

\section{Publisher's Note}

Springer Nature remains neutral with regard to jurisdictional claims in published maps and institutional affiliations.

Ready to submit your research? Choose BMC and benefit from:

- fast, convenient online submission

- thorough peer review by experienced researchers in your field

- rapid publication on acceptance

- support for research data, including large and complex data types

- gold Open Access which fosters wider collaboration and increased citations

- maximum visibility for your research: over $100 \mathrm{M}$ website views per year

At $\mathrm{BMC}$, research is always in progress.

Learn more biomedcentral.com/submissions 